\title{
A Guideline for Designing Chalcogenide-Based Glasses for Threshold Switching Characteristics
}

\author{
S. Prakash, S. Asokan, and D. B. Ghare
}

\begin{abstract}
Chalcogenide-based switching materials have potential applications in power control and information storage. In this work, an approach has been suggested to design chaclcogenidebased amorphous materials for threshold or memory switching characteristics. Using this guideline, glasses have been formed in a new chalcogenide Al-Ge-As-Te system. All the samples studied have been found to exhibit threshold switching characteristics, which proves the validity of the suggested guideline.
\end{abstract}

\section{INTRODUCTION}

$\mathbf{M}$ ANY researchers have investigated the switching characteristics in chalcogenide glasses, particularly to enhance the device performance and also to understand the mechanism of switching and various applications of these devices [1]-[6]. However, there is no guideline to choose the desired material composition which will exhibit threshold or memory switching. In the present work, emphasis is made to give basic guidelines to choose materials that will exhibit threshold switching phenomena. With such basic set of rules a new chalcogenide Al-Ge-As-Te glassy material compositions were formed by melt quenching method, and their $I-V$ characteristics were found to be as desired.

\section{Formulation OF THE GUIDELINE}

\section{A. Selection of the Basic Chalcogen Element}

It has been observed that, compared to Te-based glasses, Se-based ternary and binary glasses always exhibit memory characteristics. This can be explained on the basis of the compressibility and atomic radii of Se and Te atoms. In case of Se the compressibility and atomic radii are $11 \times 10^{-12} \mathrm{~cm}^{2} /$ dyn and $1.17 \AA$, respectively, and for Te they are $4.35 \times 10^{-12}$ $\mathrm{cm}^{2} /$ dyn and $1.37 \AA$, respectively. Memory switching in chalcogenides is mostly a thermal process, which involves phase transformation from amorphous to crystalline state. During the process of switching Se atoms can easily move because of lesser atomic radii and also their bond angles can be easily deformed due to the higher compressibility. In addition, the elasticity of Se glasses is less compared to Te glasses. Hence, in Se-based glasses, the tendency toward regaining its initial state is less after deformation and as a result they always exhibit memory. On the other hand, Te-based glasses are more

Manuscript received June 10, 1996; revised October 3, 1996.

S. Prakash and S. Asokan are with the Department of Instrumentation, Indian Institute of Science, Bangalore-560012, India.

D. B. Ghare is with the Department of Electrical Communication Engineering, Indian Institute of Science, Bangalore-560012, India.

Publisher Item Identifier S 0741-3106(97)01243-3. elastic and can regain their initial state if the energy to deform is removed. Therefore, the main constituent in a chalcogenide threshold glass must be Te.

\section{B. Overall Network Connectivity of the System}

Memory switching in chalcogenide glasses is known to involve crystallization of the material. The connectivity of the structural network of a chalcogenide glass has an important role in the crystallization of the material and consequently on the memory switching. If the network connectivity is high, the steric hinderences for structural reorganizations will be higher. Hence, the crystallization becomes more difficult and the material is less likely to show memory switching.

One way to increase the network connectivity in a chalcogenide glass is to add higher coordinated atoms. The concentration of the higher coordinated additive has to be properly chosen to form a threshold material. In order to understand the effect of higher coordinated additive atoms on the overall connectivity, let us consider the Ge-Te glassy system. The variation of different types of bonds with composition can be simulated using a simple procedure. First, the total number of different types of atoms present in a given quantity of sample for a particular composition is ascertained. Subsequently, the number of different types of bonds are calculated using the coordination numbers of the constituents (obtained by $8-\mathrm{N}$ rule [7]) and based on the following assumptions [8]: 1) heteropolar bonds are favored over homopolar bonds; and 2) bonds are formed in the order of decreasing energies. Fig. 1 shows the variation of Te-Te bonds with composition in the Ge-Te glassy system obtained using the above procedure. It can be seen that, at a composition around 34 atom \% of $\mathrm{Ge}, \mathrm{Te}-\mathrm{Te}$ bonds completely vanish and $\mathrm{Ge}-\mathrm{Te}$ bonds become maximum. Therefore, it can be concluded that a minimum of 34 atom \% of four-fold coordinated $\mathrm{Ge}$ is required to ensure complete connectivity. Such a material has more probability to exhibit threshold switching. However with more concentration of higher coordinated additive atoms, it is difficult to form homogenous glasses in a chalcogenide system. Hence, to get a bulk glass which also exhibits threshold switching, it becomes necessary to reduce the concentration of four-fold coordinated atoms and compensate this reduction by the addition of other elements. However, it is mandatory to maintain a minimum percentage of four-fold coordinated elements, below which the sample may exhibit memory behavior. It was suggested by Phillips and Thorpe [9] that the structural rigidity of a chalcogenide glass percolates with composition. At a composition corresponding to a mean coordination of 2.4 (known as the 


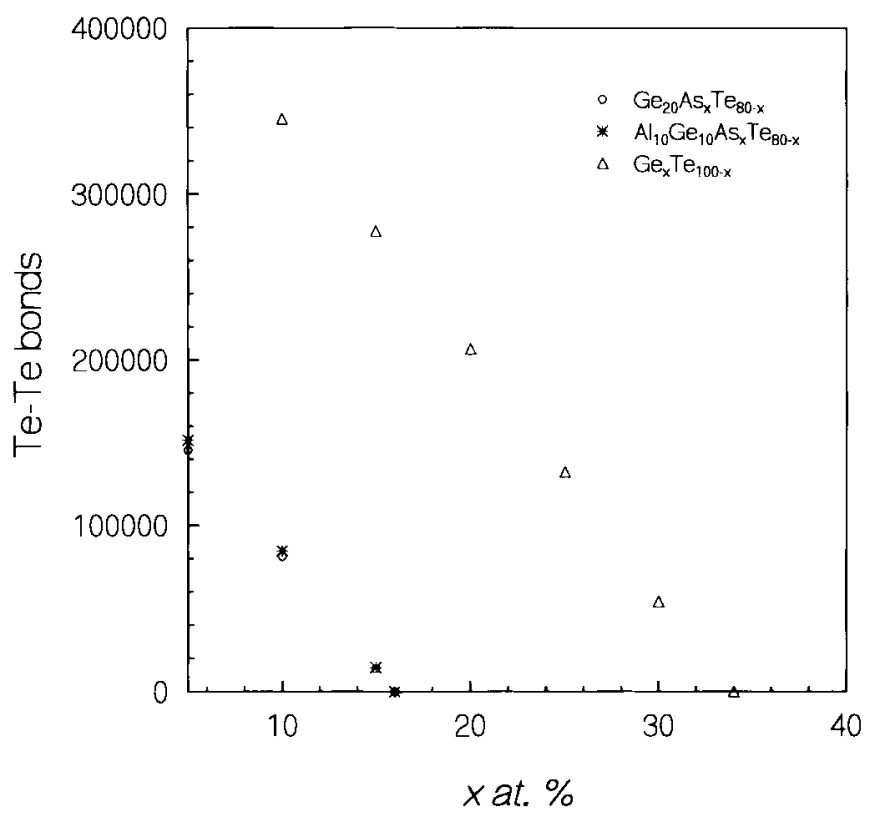

Fig. 1. Variation of number of $\mathrm{Te}-\mathrm{Te}$ bonds with composition in $\mathrm{Ge}-\mathrm{Te}$, $\mathrm{Ge}-\mathrm{As}-\mathrm{Te}$, and $\mathrm{Al}-\mathrm{Ge}-\mathrm{As}-\mathrm{Te}$ glasses.

rigidity percolation threshold), a chalcogenide glass exhibits a transformation from a floppy polymeric material to a rigid solid. Network rigidity is also an important aspect in switching as it reduces the crystallization tendency [10] and enhances the ability to show threshold switching. In a IV-VI chalcogenide glass, the percolation threshold corresponds to 20 atom $\%$ of four-fold coordinated atoms. Based on the above, it can be concluded that the chalcogenide glass should contain this minimum amount of four-fold coordinated elements to show threshold behavior, in addition to other additives.

The choice of the other higher coordinated additive is rather restricted. The natural choice of the additives is from $\mathrm{V}$ group, as they satisfy both the criteria of higher connectivity and also help to form glass easily. Within the $\mathrm{V}$ group, there is yet another restriction based on the metallicity of the element. With the addition of more metallic elements, the crystallization ability of chalcogenide glasses generally increases [11]. Therefore, the threshold switching material should contain appropriate amount of As or $\mathrm{P}$, in addition to $\mathrm{Ge}(\mathrm{Si})$ and $\mathrm{Te}$. Arsenic is preferred over Phosphorous due to difficulties in glass preparation and handling.

The quantity of arsenic required can be also be fixed by considering the bond statistics. For example, in the $\mathrm{Ge}_{20} \mathrm{As}_{x} \mathrm{Te}_{80-x}$ system the number of $\mathrm{Te}-\mathrm{Te}$ bonds vary with composition as shown in Fig. 1. It can be seen from Fig. 1. that at 16 atomic percentage of arsenic, the Te-Te bond completely vanishes, which indicates that the required network connectivity can be achieved at this composition. Similar results have also been obtained for $\mathrm{Al}_{10} \mathrm{Ge}_{10} \mathrm{As}_{x} \mathrm{Te}_{80-x}$ system in which $\mathrm{Al}$ is known to coordinate tetrahedrally [12] (Fig. 1).

In a nutshell, minimum of 20 atom $\%$ of four-fold coordinated element with 16 atom \% of three-fold coordinated As and remaining Te should be present to exhibit threshold switching characteristics is the proposed guideline. Chalcogenide mate-

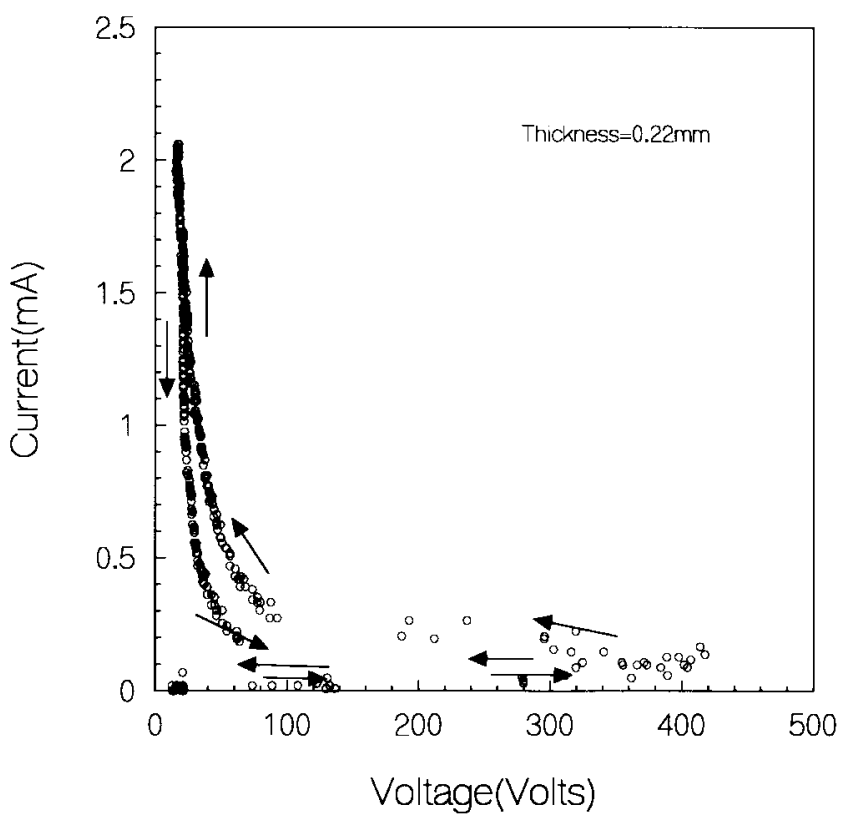

Fig. 2. Representative static $I-V$ characteristics of $\mathrm{Al}_{10} \mathrm{Ge}_{10} \mathrm{As}_{40} \mathrm{Te}_{40}$ glass showing threshold characteristics

rial compositions violating the above guideline are likely to exhibit memory switching.

It should be noted that the suggested amounts of the fourfold and the three-fold coordinated additives is only the minimum required and it is always desirable to choose higher concentrations (if glasses can be formed), with larger mean coordination numbers, so that stable and repeatable threshold characteristics can be obtained.

\section{EXPERIMENTAL DETAILS}

Considering the above guidelines, semiconducting $\mathrm{Al}_{10} \mathrm{Ge}_{10} \mathrm{As}_{x} \mathrm{Te}_{80-x}$, glasses of four different compositions were prepared in the As atomic percentage range $25 \leq x \leq 40$, by conventional melt quenching method. The As prepared samples were confirmed to be amorphous by X-ray diffraction technique and all the samples were found to exhibit $T_{g}$ in Differential Scanning Calorimetry. Samples of about 0.22-mm thickness, were polished using a fine emery (600 grade). The polished samples were held in a special holder, between a point contact top electrode and a flat plate bottom electrode, both made of brass, using a spring loading mechanism. The $I-V$ characteristics of the $\mathrm{Al}_{10} \mathrm{Ge}_{10} \mathrm{As}_{x} \mathrm{Te}_{80-x}$, glasses were studied using a custom-built PC-based system [13]. A constant current was passed through the sample and the voltage developed across it was measured. It was found that all the Al-Ge-As-Te samples prepared using the suggested guidelines, exhibited threshold switching behavior. Fig. 2 shows the typical $I-V$ characteristics of $\mathrm{Al}_{10} \mathrm{Ge}_{10} \mathrm{As}_{40} \mathrm{Te}_{40}$ composition, exhibiting threshold characteristics, which proves the validity of the guideline. In the present study, four representative samples were taken in the composition range $(25 \leq x \leq 40)$ to verify the guideline. However, more number of samples can be prepared in this range which will also show threshold behavior. 
TABLE I

Electrical Switching Behavior of Al-As-Te Glasses

\begin{tabular}{|c|c|c|}
\hline SERIES & COMPOSITION & SWITCHING TYPE \\
\hline $\mathrm{Al}_{20} \mathrm{As}_{\mathrm{x}} \mathrm{Te}_{80-\mathrm{x}}$ & $\begin{array}{l}\mathrm{Al}_{20} \mathrm{As}_{5} \mathrm{Te}_{75} \\
\mathrm{Al}_{20} \mathrm{As}_{15} \mathrm{Te}_{65} \\
\mathrm{Al}_{20} \mathrm{As}_{25} \mathrm{Te}_{55} \\
\mathrm{Al}_{20} \mathrm{As}_{35} \mathrm{Te}_{45}\end{array}$ & $\begin{array}{l}\text { Memory } \\
\text { Threshold } \\
\text { Threshold } \\
\text { Threshold }\end{array}$ \\
\hline $\mathrm{Al}_{\mathrm{x}} \mathrm{As}_{40-\mathrm{x}} \mathrm{Te}_{60}$ & $\begin{array}{l}\mathrm{Al}_{5} \mathrm{As}_{35} \mathrm{Te}_{60} \\
\mathrm{Al}_{10} \mathrm{As}_{30} \mathrm{Te}_{60} \\
\mathrm{Al}_{15} \mathrm{As}_{25} \mathrm{Te}_{60} \\
\mathrm{Al}_{20} \mathrm{As}_{20} \mathrm{Te}_{60}\end{array}$ & $\begin{array}{l}\text { Memory } \\
\text { Memory } \\
\text { Memory } \\
\text { Threshold }\end{array}$ \\
\hline $\mathrm{Al}_{\mathrm{x}} \mathrm{As}_{40} \mathrm{Te}_{60-\mathrm{x}}$ & $\begin{array}{l}\mathrm{Al}{ }_{5} \mathrm{As}_{40} \mathrm{Te}_{55} \\
\mathrm{Al}_{10} \mathrm{As}_{40} \mathrm{~T} \mathrm{e}_{50} \\
\mathrm{Al}_{15} \mathrm{As}_{40} \mathrm{~T} \mathrm{e}_{45} \\
\mathrm{Al}_{20} \mathrm{As}_{40} \mathrm{Te}_{40}\end{array}$ & $\begin{array}{l}\text { Memory } \\
\text { Memory } \\
\text { Memory } \\
\text { Threshold }\end{array}$ \\
\hline
\end{tabular}

Table I consolidates the switching behavior of Al-As-Te glasses of different compositions [14], which confirms the validity of the proposed guideline. Threshold switching samples in the Ge-As-Te glassy system are also found to obey the guideline [15].

\section{CONCLUSION}

A guideline has been formulated to choose chalcogenidebased glasses, which will exhibit threshold characteristics. Based on that, it was possible to identify a new quartenary glass system (Al-Ge-As-Te) which exhibits threshold switching characteristics. The new approach suggested will be useful to design a chalcogenide material for memory or threshold switches for different applications.

\section{ACKNOWLEDGMENT}

The authors gratefully acknowledge the help of their colleagues R. Arvind and S. Murugavel.

\section{REFERENCES}

[1] IEEE Trans. Electron Devices, Special issue on amorphous semiconductor devices, vol. ED-20, Feb. 1973.

[2] D. Adler, H. K. Henisch, and N. F. Mott, "The mechanism of threshold switching in amorphous alloys," Rev. Mod. Phys., vol. 50, no. 2, p. 209, 1978.

[3] S. R. Ovshinsky and D. Adler, "Progress in the science and applications of amorphous materials," J. Non-Cryst. Solids, vol. 90, p. 229, 1987.

[4] A. K. Vohra and K. K. Srivastva, "Microwave switching and A.C. conductivity of memory glass $\mathrm{As}_{10} \mathrm{Ge}_{15} \mathrm{Te}_{75}$," Phys. Stat. Sol. A, vol. 121, p. 341, 1990.

[5] D. P. Gosain, T. Shimizu, M. Ohmura, M. Suzuki, T. Bando, and S. Okano, "Some properties of $\mathrm{Sb}_{2} \mathrm{Te}_{3-x} \mathrm{Se}_{x}$ for nonvolatile memory based on phase transition," J. Mater. Sci., vol. 26, p. 3271, 1991.

[6] K. Naayama, T. Kitagawa, M. Ohmura, and M. Suzuski, "Non-volatile memory based on phase transition in chalcogenide thin films," Jpn. J. Appl. Phys., vol. 32, p. 564, 1993.

[7] N. F. Mott and E. A. Davis, Electronic Processes in Non-Crystalline Materials. Oxford, U.K.: Clarendon, 1979.

[8] W. H. Zacharisen, J. Amer. Chem. Soc., vol. 54, p. 3841, 1932.

[9] J. C. Phillips and M. F. Thorpe, "Constraint theory, vector percolation and glass formation," Solid State Commun., vol. 53, p. 699, 1985.

[10] S. S. K. Titus, R. Chatterjee, S. Asokan, and A. Kumar, "Electrical switching and short-range order in As-Te glasses," Phys. Rev. B, vol. 48, no. 19, p. 14650, 1993.

[11] Z. U. Borizova, Glassy Semiconductors. London, U.K.: Plenum, 1981.

[12] P. C. Taylor, Z. M. Saleh, and J. Liu, "A general structural model for amorphous semiconductors," J. Non-Cryst. Solids, vol. 114, p. 25, 1989.

[13] R. Chatterjee, S. Asokan, and S. S. K. Titus, "A PC-based system for studying electrical switching in amorphous semiconductors," Rev. Sci. Instrum., vol. 65, p. 2382, 1994.

[14] S. Murugavel and S. Asokan, "Network related electrical switching in Al-As-Te glasses," Semicond. Sci. Technol., communicated.

[15] R. Pinto, "Threshold and memory switching in thin films of the chalcogenide systems Ge-As-Te and Ge-As-Se," Thin Solid Films, vol. 7, p. 391, 1971. 